\title{
ANÁLISE DO SEGMENTO EXPORTADOR DA AVICULTURA BRASILEIRA NO PERÍODO DE 1996 A 2004 ${ }^{1}$
}

\author{
Dênis Antônio da Cunha ${ }^{2}$ \\ Roberto Serpas Dias ${ }^{3}$
}

\begin{abstract}
Resumo - Esse trabalho teve o objetivo principal de analisar e avaliar a estrutura e dinâmica de mercado do segmento exportador da avicultura brasileira, no período de 1996 a 2004. A metodologia foi constituída pelos índices de concentração $\mathrm{CR}_{\mathrm{k}}$ e HHI, calculados para caracterizar a estrutura de mercado. Verificou-se também a dinâmica de posicionamento do setor (turnover). Os resultados encontrados indicam que a concentração do setor é alta, razão da necessidade de grandes investimentos para atuação no mercado internacional, e que o posicionamento das empresas alterou-se, principalmente devido às que perderam posições em relação ao ano inicial. Contudo, a concentração tem diminuído e há evidências de que o poder de mercado não esteja sendo utilizado pelas firmas, com vistas em diminuir o bem-estar dos consumidores.
\end{abstract}

Palavras-Chave: Setor avícola, exportações, concentração de mercado, dinâmica setorial.

\section{Introdução}

Atualmente, o Brasil é o maior exportador mundial de frango. A avicultura brasileira tem apresentado grande dinamismo na produção, industrialização, comercialização e progresso técnico, além de sua contribuição para geração de emprego, renda e divisas de exportação ao país.

O desempenho das exportações avícolas é reflexo da reorganização da produção de carnes ocorrida no Brasil a partir da década de 70. Empresas especializadas na produção de suínos diversificaram-se na produção de aves, mudança impulsionada pela oferta de créditos para investimentos de longo prazo, associada à utilização de tecnologias importadas e

${ }^{1}$ Recebido em 15/08/2005 Aceito em 19/12/2005.

${ }^{2}$ Graduando em Ciências Econômicas pela Universidade Federal de Viçosa. E-mail: denisufv@gmail.com

${ }^{3}$ Professor do Departamento de Economia da Universidade Federal de Viçosa. E-mail: rsdias@ufv.br 
melhorias nas técnicas de manejo, nutrição e sanidade (Skora, 1994 apud Canever, 1997).

Ainda na década de 70, após expressivo desenvolvimento tecnológico, o setor avícola nacional exportou os primeiros lotes de carne de frango. Desde então, na produção agroindustrial de carnes, a avicultura apresentase com o maior nível de organização e capacitação para competir no mercado internacional. Numa análise comparativa entre as exportações de carne bovina, suína e aves, o grande destaque comercial é o frango de corte.

A avicultura consolidou-se como o segundo maior no ranking das exportações do agronegócio brasileiro, superado apenas pelo complexo da soja; na pauta geral brasileira, está em sexto lugar. Essas exportações são importantes para o equilíbrio das contas externas do país e para a manutenção de, aproximadamente, quatro milhões de empregos. Além do impacto direto na renda e no emprego, impacta setores para trás, como a produção de insumos (soja e milho), e também para frente, como transporte, refrigeração e serviços.

Segundo o Instituto Paranaense de Desenvolvimento Econômico e Social (Ipardes, 2002), o desempenho favorável das exportações avícolas brasileiras é explicado pelo baixo preço relativo da carne de frango, pela sua imagem como produto saudável junto ao consumidor e pela sua aceitação pela maioria das culturas e religiões.

O mercado internacional tem se mostrado como importante complemento à demanda interna. $\mathrm{O}$ crescimento da produção nacional é impulsionado pelo aumento das vendas externas, que induzem ganhos de produtividade, dado o acesso da indústria nacional a novas tecnologias e a padrões de consumo diferenciados.

No Brasil, as maiores firmas exportadoras realizam a produção por meio de contratos de parceria avícola com produtores rurais. De acordo com Garcia (2004), as empresas processadoras realizam a produção de matrizes, fornecem o pinto de um dia, as rações e assistência técnica e 
veterinária, além do transporte, abate e comercialização do frango. Por sua vez, o produtor providencia as instalações e os equipamentos indicados no contrato e responsabiliza-se pela mão-de-obra e pela engorda do frango.

Uma possível implicação desse modo de organização da produção é o poder de mercado, entendido como a possibilidade de uma firma manter o preço de venda acima daquele fixado por seus concorrentes, sem prejuízo para sua participação no mercado. Entretanto, há perdas para a sociedade no que diz respeito à redução na oferta do produto. Diante desse fato, atentou-se para a necessidade de se analisar o segmento exportador da avicultura brasileira, que é formado por grandes empresas que interagem com outras menores que apenas produzem frango.

O período considerado no estudo foi de 1996 a 2004, dada a disponibilidade de dados. Foram mensuradas as exportações brasileiras de frango nesse intervalo, destacando suas principais características. Calculou-se o grau de concentração do segmento exportador do complexo avícola e realizouse a análise de posicionamento (turnover), a fim de avaliar sua dinâmica competitiva.

\section{Metodologia}

\subsection{Teoria da Organização Industrial}

Os estudos sobre Organização Industrial (OI) surgiram na década de 30, a partir dos trabalhos de Hall e Hitch, Mason e Coase. A teoria foi desenvolvida como uma reação à microeconomia tradicional e, desde o início, esteve relacionada com questões de política pública. De acordo com Azevedo (1998), os primeiros trabalhos de OI questionavam o princípio marginalista, segundo o qual a firma tinha como único objetivo a maximização do lucro, mediante o conhecimento de suas funções de custo e demanda. A nova visão considera a interdependência das ações da firma e de suas concorrentes na determinação das principais variáveis econômicas, como preço e produção. 
Para Scherer e Ross (1990), apud Farina et al. (1997), a OI tem interesse em conhecer como os processos de mercado orientam as atividades dos produtores para atender à demanda dos consumidores e como esses processos falham e se ajustam para aproximar-se de um padrão ideal. Coase (1972), apud Farina et al. (1997), argumentou que o verdadeiro objetivo da OI é determinar as forças responsáveis pela organização da indústria, como essas forças têm se modificado ao longo do tempo e que efeitos podem ser esperados de mudanças na forma de organização da indústria.

Não obstante essa controvérsia a respeito do escopo da OI, pode-se considerar, conforme Farina et al. (1997), que a preocupação central de sua análise são as causas e conseqüências do poder de mercado. A OI trata das estratégias competitivas das firmas em condições de interdependência oligopolista e seus efeitos sobre o ambiente competitivo (criação e manutenção de barreiras à entrada, expulsão de rivais efetivos e potenciais, exploração e extensão do poder de monopólio).

Uma das versões mais tradicionais de OI, o Paradigma EstruturaConduta-Desempenho (ECD), busca avaliar o desempenho de determinado mercado e compará-lo a uma situação ideal de concorrência perfeita. É a tentativa de mensurar o quanto as imperfeições de mercado limitam sua capacidade de atender à demanda de bens e serviços pela sociedade (Azevedo, 1998).

$\mathrm{Na}$ análise proposta pelo modelo ECD, a conduta da firma (estratégias adotadas) determina o desempenho do sistema econômico. O conjunto de estratégias disponíveis é resultado da estrutura de mercado em que a empresa se insere. As estruturas de mercado, por sua vez, dependem das condições básicas de oferta e demanda, que compreendem características do produto, consumidores e tecnologia, aparato legal, taxa de crescimento dos mercados, etc (Azevedo, 1998). 


\section{2. Índices de Concentração Industrial}

Utilizaram-se, neste trabalho, os índices Razão de Concentração $\left(\mathrm{CR}_{\mathrm{k}}\right)$ e Índice de Hirshman-Herfindahl (HHI), com base na metodologia descrita por Hoffmann (1991).

- Razão de Concentração $\left(\mathrm{CR}_{\mathrm{k}}\right)$

A razão de concentração das $\mathrm{k}$ maiores empresas calcula a proporção do valor total que é dominada por essas empresas pertencentes a determinado setor (Equação1):

$$
C R_{k}=\sum_{\mathrm{i}=1}^{\mathrm{k}} Y_{i},
$$

em que ké o número de empresas analisadas e $\mathrm{Y}_{\mathrm{i}}$, proporção de mercado pertencente à i-ésima empresa.

\section{- Índice de Hirshman-Herfindahl (HHI)}

O Índice de Hirshman-Herfindahl é definido de acordo com a Equação 2:

$$
H H I=\sum_{\mathrm{i}=1}^{\mathrm{N}}\left(Y_{i}\right)^{2},
$$

em que $\mathrm{N}$ é o número de empresas do setor e $\mathrm{Y}_{\mathrm{i}}$, proporção do mercado pertencente à i-ésima empresa.

O valor máximo para HHI é observado numa situação em que o setor é constituído por uma única empresa, ou seja, é um monopólio $(\mathrm{HHI}=1)$. $\mathrm{O}$ valor do índice estará próximo de zero quando a produção setorial estiver dividida de maneira relativamente igualitária entre grande número de empresas. 


\subsection{Analise de Turnover}

A dinâmica de competição do setor foi avaliada pela análise de turnover, que consiste no registro das mudanças de posicionamento que ocorreram entre empresas em determinado ranking, de um ano para outro. A metodologia aqui adotada, proposta por Joskow (1960), descreve o número de firmas que, no final do período considerado, permaneceram dentro do mesmo grupo, mudaram de posição ou saíram do mercado e, ou, deixaram de ser registradas no ranking inicialmente delimitado (Tabela 1).

Tabela 1 - Dinâmica de posicionamento (turnover) de empresas do segmento exportador da avicultura brasileira

\section{Ano inicial Ano final}

Grupo Ranking Grupo A Grupo B Grupo... Saiu

TOTAL

\begin{tabular}{lcccccc}
\hline A & $(1-5)$ & 2 & 1 & $\cdots$ & 2 & 5 \\
B & $(6-10)$ & 1 & 3 & $\cdots$ & 1 & 5 \\
$\cdots$ & $\cdots$ & $\cdots$ & $\cdots$ & $\cdots$ & $\cdots$ & $\cdots$ \\
\hline TOTAL & 3 & 4 & & 3 & 10 \\
\hline
\end{tabular}

Fonte: adaptado de Joskow (1960).

\subsection{Fonte de Dados}

Os dados utilizados neste estudo referem-se às exportações do setor no período de 1996 a 2004 e foram coletados na home-page da Associação 
Brasileira dos Produtores e Exportadores de Frango - ABEF (http:// www.abef.com.br).

\section{Resultados e discussão}

\subsection{As exportações brasileiras de frango, 1996 a 2004}

Dados da ABEF indicam que as exportações brasileiras de frango evoluíram de 568,8 mil toneladas, em 1996, para 2.425 mil toneladas, em 2004, um aumento de $326,4 \%$ no período. Em 2004, a receita cambial com vendas internacionais do setor atingiu US\$2,6 bilhões, e o país foi responsável por $42 \%$ das exportações mundiais do produto. Enquanto no início dos anos 1990 o Brasil vendia apenas para 24 países, em 2004 o número de mercados aumentou para 134.

Esses resultados estão relacionados com diversificação e adequação dos produtos exportados, a fim de atender às crescentes demandas e satisfazer a hábitos específicos de cada mercado consumidor. Vantagens como clima favorável e grande produção de grãos, além das constantes inovações tecnológicas, reduzem o custo de produção e tornam o país altamente produtivo e, conseqüentemente, competitivo no mercado externo.

Outra característica a ser destacada nas exportações da avicultura brasileira refere-se à tendência de adição de valor ao produto final, por meio do crescimento das vendas de partes de aves, em detrimento das exportações de frangos inteiros. Em 1996, os cortes de frango representavam, aproximadamente, $50 \%$ das exportações totais do segmento e, em 2004, foram responsáveis por cerca de $60 \%$. Essa inversão no mix de produtos exportados é importante na medida em que representa a "descomoditização" do frango; os cortes, conforme Jank (1997), geram uma adição próxima de $50 \%$ de valor ao produto, em relação ao frango inteiro.

Entre as causas do expressivo desempenho da avicultura brasileira estão 
as mudanças nos fluxos de comércio, motivadas por questões de ordem sanitária, como a influenza aviária. Anúncios da descoberta de focos da doença vêm circulando no mercado mundial avícola desde a segunda metade de 2001. O Brasil, detentor do status de país livre da doença, teve a chance de ocupar os espaços abertos pela queda de produção nos países afetados, alguns grandes produtores e exportadores. O país beneficiou-se, sobretudo, dos preços e, em menor medida, da expansão do mercado.

Não obstante a expressividade de suas exportações avícolas, o Brasil é prejudicado por barreiras de natureza econômica, comercial (tarifária) e, ou, cultural. Estados Unidos e União Européia, entre outras regiões, impõem restrições sanitárias, exigem certificados ou concedem subsídios ao seu produto, o que impede o pleno funcionamento da concorrência mundial.

\section{2. Índices de concentração e análise de turnover}

A concentração industrial será tanto mais alta quanto maior for a desigualdade na repartição das parcelas de mercado entre as firmas que compõem uma indústria. A Tabela 2 apresenta os principais índices calculados neste trabalho. $\mathrm{ACR}_{\mathrm{k}}$ possibilitou a mensuração das parcelas de mercado controladas pelas quatro e oito maiores empresas. O índice $\mathrm{HHI}$ corrobora os resultados encontrados pelos dois primeiros. 
Tabela 2 - Índices de concentração no segmento exportador da avicultura brasileira, 1996 a 2004

\begin{tabular}{cccccccccc}
\hline & $\mathbf{1 9 9 6}$ & $\mathbf{1 9 9 7}$ & $\mathbf{1 9 9 8}$ & $\mathbf{1 9 9 9}$ & $\mathbf{2 0 0 0}$ & $\mathbf{2 0 0 1}$ & $\mathbf{2 0 0 2}$ & $\mathbf{2 0 0 3}$ & $\mathbf{2 0 0 4}$ \\
\hline $\boldsymbol{C R}_{4}$ & 0,82 & 0,87 & 0,87 & 0,84 & 0,81 & 0,80 & 0,76 & 0,75 & 0,71 \\
$\boldsymbol{C R}_{\boldsymbol{8}}$ & 0,98 & 0,98 & 0,95 & 0,92 & 0,93 & 0,92 & 0,90 & 0,88 & 0,83 \\
$\boldsymbol{H H I}$ & 0,1967 & 0,2073 & 0,2119 & 0,2013 & 0,1818 & 0,1722 & 0,1546 & 0,1534 & 0,1495
\end{tabular}

Fonte: Dados da pesquisa.

Os dados da Tabela 2 mostram que houve diminuição na concentração de mercado nos três níveis estudados, ao longo do período em questão (apesar de ter havido pequeno aumento na concentração nos anos de 1996 a 1998). A parcela de mercado dominada pelas quatro principais empresas passou de $82 \%$, em 1996, para $71 \%$, em 2004, queda de $13,4 \%$; as oito maiores empresas, que detinham $98 \%$ em 1996, passaram para $83 \%$, em 2004. O índice HHI apresentou comportamento semelhante em relação aos mesmos intervalos, porém em diferentes proporções.

Apesar da tendência de desconcentração, as firmas líderes dominam, aproximadamente, três quartos das exportações. Ao contrário do abate, as exportações são realizadas por reduzido número de grandes grupos empresariais. Essa característica, segundo Jank (1997), mostra que as firmas líderes optam por operar produtos sobre os quais detêm maior controle da oferta e podem aproveitar as economias de escala (os sistemas de "parceria avícola", por exemplo), e, ou, sobre produtos de maior valor agregado, ou seja, onde for possível explorar as vantagens diferenciação via processamento industrial (partes, cortes temperados, embutidos, enlatados, etc).

A análise de turnover foi realizada nas quinze maiores empresas exportadoras do setor avícola brasileiro de 1999, observando suas mudanças no ranking até 2004 (Tabela 3). 
Tabela 3 - Análise de turnover das quinze maiores empresas exportadoras da indústria avícola no Brasil, 1999 e 2004

Empresas por ranking

\begin{tabular}{lccccc}
\hline \multicolumn{2}{c}{1999} & \multicolumn{2}{c}{$\mathbf{2 0 0 4}$} & \multirow{2}{*}{$\begin{array}{c}\text { Saiu ou não foi } \\
\text { registrada entre as 15 }\end{array}$} \\
\cline { 1 - 4 } Grupo & Ranking & Grupo A & Grupo B & Grupo C & 1 \\
\hline A & $(1-5)$ & 4 & 0 & 0 & 1 \\
B & $(6-10)$ & 1 & 2 & 1 & 3 \\
C & $(11-15)$ & 0 & 0 & 2 & 5 \\
\hline TOTAL & & 5 & 2 & 3 & \\
\hline
\end{tabular}

Fonte: Dados da pesquisa.

No período de 1999 a 2004 (Tabela 3), das cinco empresas que compunham originalmente o grupo $\mathrm{A}$, uma saiu do horizonte de análise enquanto as demais permaneceram, o que demonstra a estabilidade dos maiores exportadores. Nos grupos $\mathrm{B}$ e C houve alternâncias significativas, com destaque para uma firma do grupo $\mathrm{B}$, que conseguiu atingir nível mais elevado. $\mathrm{O}$ grupo $\mathrm{C}$ demonstrou forte suscetibilidade às mudanças de mercado, uma vez que nele foi registrado maior número de saídas de firmas do ranking.

\section{Conclusões}

A avicultura de corte brasileira vem passando, nos últimos anos, por mudanças importantes, em relação a aspectos tecnológicos, produtivos e operacionais. O desempenho do setor, principalmente no que concerne às suas exportações, é considerado melhor que o de outros tipos de carnes produzidas pelo Brasil. 
Com vistas em atender às especificidades de cada mercado, os exportadores do complexo avícola nacional precisam de processos produtivos complexos, evolução tecnológica constante, mão-de-obra altamente qualificada e maior esforço de vendas. Essa proposição é confirmada pelo fato de as duas maiores firmas realizarem, em média, $48 \%$ das vendas externas do segmento.

Entretanto, o poder de mercado das grandes empresas exportadoras de frango não tem diminuído o bem-estar dos consumidores. As exportações não competem com o abastecimento interno, mas são um estímulo ao aumento da produção, o que afasta a possibilidade de redução na oferta. Soma-se a isso o fato de que o preço do quilo de frango praticado no mercado nacional é um dos mais baixos do mundo (menos da metade do que é cobrado, por exemplo, do consumidor norte-americano).

Finalmente, destaca-se a tendência de diminuição na parcela de mercado dominada pelas firmas líderes. Anualmente, novas empresas têm atingido os requisitos requeridos pelo mercado internacional, o que aumenta a possibilidade de manutenção da posição do país como maior exportador mundial de frangos.

\section{Referências}

ASSOCIAÇÃO BRASILEIRA DOS PRODUTORES E EXPORTADORES DE FRANGO - ABEF. Disponível em: $<$ http:// www.abef.com.br/relatorios>. Acesso em 25 Mai. 2005).

AZEVEDO, P. F. Organização Industrial. In: PINHO, D. B.; VASCONCELLOS, M. A. S. (Orgs.).Manual de Economia. 3 ed. São Paulo: Saraiva, 1998. p. 195-222.

CANEVER, M. D. Competitividade Relativa Entre as Cadeias de Frango Brasileira e Argentina. Viçosa: UFV, 1997. 128 p. Dissertação (Mestrado em Economia Rural) - Universidade Federal de Viçosa, Viçosa. 
FARINA, E.M.M.Q.; SAES, M.S.; AZEVEDO, P.F., Competitividade: Mercado, Estado e Organizações. São Paulo: Pioneira, 1997. 286p.

GARCIA, L. A. F. Economias de Escala na produção de frangos no Brasil. Piracicaba: ESALQ, 2004. 114 p. Tese (Doutorado em Economia Aplicada) - Escola Superior de Agricultura Luiz de Queiroz, Piracicaba.

HOFFMANN, R. Estatística para Economistas. São Paulo: Pioneira, 1991. 426p.

IPARDES - Instituto Paranaense de Desenvolvimento Econômico e Social. Análise da Competitividade da Cadeia Agroindustrial de Carne de Frango no Estado do Paraná. Curitiba: IPARDES, 2002. $230 \mathrm{p}$.

JANK, M. S. Organizações e Estratégias nas Organizações Brasileiras de Carnes. In: CARVALHO, F.; VIEIRA, W. (Eds.). Mercosul: Agronegócios e Desenvolvimento Econômico. Viçosa: UFV, 1997. p. 109-153.

JOSCOW, J. Structural Indicia: Rank- Shift Analysis as a Supplement to Concentration Ratios. Review of Economic and Statistics XLII, p. 113 - 116. Fev. 1960.

\footnotetext{
Abstract - This paper has the main goal of analyzing and evaluating the structure and dynamics of the market from the exporting section of Brazilian chicken raising, from 1996 to 2004. Concentration rates were calculated in order to measure the market share which are dominated by the main companies. The dynamics of the sector position (turnover) was also checked. The reached results point that the sector concentration is higt, and great investments are necessary to the performance in the international market; the placement of the companies was changed mainly due to the ones which had lost positions compared to the first year. However, the concentration has decreased, and there is evidence that the market power hasn't been used by the companies in a sense of reducing the consumers' well being.
}

Keywords: Aviculture, exportations, market concentration, sector dynamics. 